\title{
Routine Identification of Melanoma Disease using Global and Local Features
}

\author{
Saranya S., PG Scholar Kavya S.P, M.E., Asst. Prof. \\ Dept of CSE, Sri Shakthi Institute of Engineering and Technology, Anna University, India
}

\begin{abstract}
This paper focuses on the finding, segmentation, categorization and removal of skin lesion as a literature survey. Melanoma is a category of cancer that develop from the pigment-network cells renowned as melanocytes. Melanomas usually develop in the skin other than may arise in the maw, backbone or ogle. This paper addresses two different systems for finding of fur evil in dermoscopy images. The first system uses global features and the second system uses local methods and the classifier. Therefore, melanoma is simply to identify with help of global features and local methods.
\end{abstract}

Keywords: Melanocytes, classifiers, finding, segmentation, categorization, removal, fur lesions.

\section{INTRODUCTION}

Melanoma fur lesions are analyzed by $\mathrm{ABCD}$ system which expect the infection with type like as Asymmetry, B-order, C-olor and Differential shape. Several researchers have been analyzed characteristic to identify the dermoscopic diagnose the melanoma accurately. In the dermoscopic images using simply to decrease the noise. Melanoma is to divide fraction of the melanocytic from the clearness and quiet. For fur finding, removal and segmentation a lot of actions are residential to get the grades with extra presentation. Then using the four parameter of $A B C D$ system used to allocate the score to injury $[1][2][10]$. Used to verify whether it is melanoma or non melanoma ${ }^{[10]}$. Estimate the pigmented fur injury is easier to identify melanoma. In the form of injury that contain the nevus cells in embryologic improvement for variation of melanocytes like as fur color ${ }^{[10]}$. Every factor is used to forecast the melanoma or non melanoma it is:

- Segmentation

- removal

- categorization

This beyond step is used to identify a fur injury with to ensure whether it is melanoma or non melanoma ${ }^{[10]}$. These method are mostly used on two technique that is:

1. Global features

2. Local methods

\subsection{Global features:}

Global features indicate looking entire images ${ }^{[12]}$.

\subsection{Local methods:}

Local methods indicate focusing on some exacting component of an picture ${ }^{[12]}$.

\section{MODULE DESCRIPTION}

\subsection{Segmentation}

The segmentation is the procedure of divider an picture keen on lesion and non lesion images. categorize the dermoscopy image into the part using the boundary finding system ${ }^{[1]}$.

\subsection{Extracting the Global Methods of the Image:}

Differentiate the entity with a position of global methods (e.g., color moment and histograms) with apply these character to distinguish the entity as of the environment ${ }^{[12]}$. These method contain two types of analysis it is:

\section{- Texture investigation}

- Color investigation

\subsubsection{Texture investigation}

Picture Texture Represents the spatial association of concentration and color within an image, and it can be categorized into several altered behavior. Several methods apply pixel information. A typical advance consists into compute the information of pair of nearest pixels, with the co-occurrence matrix $[3][13][15]$. 


\subsubsection{Color investigation}

The generally accepted type used in dermoscopy investigation are color data, such as the mean color and color varaiance $^{[8][13]}$.

\subsection{Extracting the Local Methods of the Images}

Position of input points is certain surrounded by the injury area; a key in direct be near categorized by a vector of local quality. This component vector represents color and texture properties in a local piece centered at the key in points ${ }^{[9]}$. While the number of key points and local methods varies from image to image, we cannot directly classifier with these data. Instead, all local methods linked with all the preparation images are gathered and used to calculate a slighter position of prototype (centroids) denote as optical expression. Then, the local methods of every dermoscopy image are assign to the nearby to optical express ${ }^{[12]}$.

\subsection{Categorization}

Classifier is then trained to discriminate melanoma lesions from non melanoma ones, using the histogram of visual words as input ${ }^{[1][14]}$.

\section{LITERATURE REVIEW}

3.1 Induction of dermoscopy in the clinical setting resulted in significant modifications in the management of melanocytic lesions. Indeed, the dermatoscope reveals a fascinating world of morphologic structures invisible to the naked eye, adding valuable information to a clinician evaluating a mole. The technique counts only a couple of decades, new research data are continuously gathering and modify the "optimal" management of melanocytic lesions. The latest trends in dermoscopy concerning early melanoma diagnosis, management of nodular lesions, diagnosis of mucosal melanoma, and digital follow up that means, texture Analysis methods to Automatic Detection of Melanoma Skin Cancer. Melanoma is one of the very dangerous cancer in skin. For diagnosis these disease required a experience, in the early stage ${ }^{[11]}$ look like a normal to harmless moles. For the less experience physicians require a automatic diagnostic tools. In automatic structure of melanoma category was apply on dermoscopy image can be assist into early stage of melanoma and melanocytic nevi lesion. Dermoscopy images are analyzed using segmentation process. The clinical setting resulted in significant modifications in the management of melanocytic lesions. Incidence of melanoma increases more rapidly than any other cancer, and this has partially been attributed to the development of highly sensitive diagnostic techniques mainly dermoscopy. The dermatoscope reveals a fascinating world of morphologic structures invisible to the naked eye, adding valuable information to a clinician evaluating a mole. The controversy whether dermoscopy improves diagnostic accuracy when assessing melanocytic lesions belongs to the history, since several lines of evidence clearly demonstrate that use of dermoscopy both enhances melanoma detection and decreases the number of unnecessary excisions. Diagnostic purposes, dermoscopy, by revealing unknown information on morphology, enhanced the understanding of nevogenesis and generated new concepts and theories. The technique counts only a couple of decades, new research data are continuously gathering and modify the "optimal" management of melanocytic lesions ${ }^{[3]}$.

3.2 SKINcure: The Malignant Melanoma Prevention and Early Detection using A Real Time Image Analysis System: The melanoma charge have increasing become passed five years. This category of tumour is unconfident to uv energy. In true period the malignant melanoma is mainly extremely requireable. Here we residential classification to avoid the before recognition. At this time we analysis the tumour images in dissimilar type of structure ${ }^{[4]}$.

3.3 Top-down shade concentration designed for entity detection: The type of the process based on aspect recognition, factor picture, and words structure and image demonstration are perform ${ }^{[5]}$. RGB Color is use to denote the notice map to compare with existing methods that merge color and contour cube on three information set contain different significant of color majority $[8][13]$. 
Table 1. Algorithm Comparison

\begin{tabular}{|c|c|c|c|c|}
\hline ALGORITHM & $\begin{array}{c}\text { TASK \& } \\
\text { TECHNIQUES }\end{array}$ & $\begin{array}{c}\text { ADVANTAG } \\
\text { ES } \\
\end{array}$ & LIMITATIONS & FEATURES \\
\hline $\begin{array}{l}\text { C4.5 } \\
\text { algorithm }\end{array}$ & --------------- & --------- & $\begin{array}{l}\text { 1. Little variant in } \\
\text { statistics can direct to } \\
\text { dissimilar decision } \\
\text { trees. } \\
\text { 2. Over fitting, }\end{array}$ & $\begin{array}{l}\text { 1. make replica } \\
\text { can be interpreted. } \\
\text { 2. simple to execute. }\end{array}$ \\
\hline ID3 Algorithm & -------------- & \begin{tabular}{lr|} 
Simple & to \\
implement & and \\
being & \\
relatively & a \\
easy & \\
procedure. & \\
\end{tabular} & $\begin{array}{l}\text { 1. require huge incisive } \\
\text { moment. } \\
2 \text {. It may produce } \\
\text { extremely lengthy system } \\
\text { which be especially } \\
\text { tough to trim. }\end{array}$ & $\begin{array}{l}\text { It produce the } \\
\text { additional } \\
\text { correctness } \\
\text { consequence than } \\
\text { the } 4.5 \text { algorithm. }\end{array}$ \\
\hline $\begin{array}{l}\text { K-Nearest } \\
\text { neighbour } \\
\mathrm{s} \\
\text { algorithm }\end{array}$ & & $\begin{array}{l}1 . \\
\text { straightforwa } \\
\text { rdness and } \\
\text { usefulness } \\
\text { 2. Intuitiveness } \\
\text { and aggressive } \\
\text { categorization } \\
\text { presentation in } \\
\text { many. }\end{array}$ & $\begin{array}{l}\text { 1. period to recover the } \\
\text { adjacent neighbours in a } \\
\text { huge instruction records } \\
\text { position can be } \\
\text { unwarranted. } \\
\text { 2. It is perceptive to } \\
\text { piercing or unrelated } \\
\text { attribute. }\end{array}$ & $\begin{array}{l}\text { 1. course need } \\
\text { not be divisible. } \\
\text { 2. nought charge } \\
\text { of the knowledge } \\
\text { procedure. }\end{array}$ \\
\hline $\begin{array}{l}\text { Navie Bayes } \\
\text { Algorithm }\end{array}$ & $\begin{array}{l}\text { 1. actual } \\
\text { period } \\
\text { categorization } \\
\text { 2. manuscript } \\
\text { categorization } \\
\text { 3. suggestion } \\
\text { organization }\end{array}$ & $\begin{array}{l}\text { 1. It is simple } \\
\text { and quick to } \\
\text { expect group } \\
\text { of experiment } \\
\text { statistics set. } \\
\text { 2. Better } \\
\text { perform } \\
\text { ance. }\end{array}$ & $\begin{array}{l}\text { 1. The exactness of } \\
\text { algorithm decreases if } \\
\text { the quantity of } \\
\text { information is less. }\end{array}$ & $\begin{array}{l}\text { 1. easy to execute. } \\
2 . \quad \text { enormous } \\
\text { computational } \\
\text { effectiveness and } \\
\text { categorization rate. }\end{array}$ \\
\hline $\begin{array}{l}\text { Support } \\
\text { Vector } \\
\text { Machine } \\
\text { Algorithm }\end{array}$ & $\begin{array}{lr}\text { 1. } & \text { categorization } \\
\text { using } & \text { 4-point } \\
\text { range } & \text { on } \\
\text { document plane }\end{array}$ & $\begin{array}{l}\text { 1. } \\
\text { Avoiding } \\
\text { over } \\
\text { fitting. } \\
\text { 2. fault rate is } \\
\text { high. }\end{array}$ & $\begin{array}{l}\text { 1. speediness and range } \\
\text { condition equally in } \\
\text { training and testing is } \\
\text { more. } \\
\text { 2. High difficulty and } \\
\text { general recollection } \\
\text { desires for } \\
\text { categorization in } \\
\text { numerous luggage. }\end{array}$ & $\begin{array}{l}\text { 1. High precision. } \\
\text { 2. Work will even if } \\
\text { data is not linearly } \\
\text { separable in the base } \\
\text { feature space. }\end{array}$ \\
\hline $\begin{array}{l}\text { Artificial } \\
\text { Neural } \\
\text { Network } \\
\text { Algorithm }\end{array}$ & $\begin{array}{l}\text { 1. It used on } \\
\text { ways shaking } \\
\text { based injure } \\
\text { recognition }\end{array}$ & $\begin{array}{l}\text { 1. instruction } \\
\text { huge } \\
\text { quantity of } \\
\text { information } \\
\text { set. }\end{array}$ & $\begin{array}{l}\text { 1. require high } \\
\text { processing time. } \\
\text { 2. complex to know } \\
\text { how many neurons } \\
\text { And layers are } \\
\text { necessary. } \\
\text { 3. learn can be slow. }\end{array}$ & $\begin{array}{l}\text { 1. It is simple to utilize, } \\
\text { with little parameter to } \\
\text { regulate. } \\
\text { 2. Easy to execute. }\end{array}$ \\
\hline
\end{tabular}

\section{CONCLUSION}

In this paper, two dissimilar strategy for the recognition of melanomas in dermoscopy images based on local and global methods. Mainly early on facility use global methods (surface, outline, and shade) connected with injury fol-lowed by a binary classifier qualified from the data. Hence this local methods is growing import in lots of image investigation problems. A second dynamic thought connected with this paper is the assessment of the position played by color and surface methods in the decision. This works consider both types of features at the same times, but they do not attempt to clarify if one of these features plays a more significant role. Both issues were tested using a information position of dermoscopy images from Hospital, and the organization parameter were tuned by comprehensive trying of many thousands of classifiers. 


\section{REFERENCES}

[1] Snehal Salunke, "Survey on Skin lesion segmentation and classification" IJIPDV Vol: 1, Issue 1, FEB 2014. [2] J. Premaladha, S. Sujitha, M. Lakshmi Priya and K.S. Ravichandran "A Survey on Melanoma Diagnosis using Image Processing and Soft Computing Techniques” Research Journal of Information Technology, 6: 6580, may 2014.

[3] Mariam A. Sheha, Amr Sharawy, Mai S.Mabrouk "Automatic Detection of Melanoma Skin Cancer using Texture Analysis" International Journal of Computer Applications (0975 - 8887) Volume 42- No.20, March 2012.

[4] Omar Abuzaghleh, Buket D. Barkana and Miad Faezipour," SKINcure: A Real Time Image Analysis System to Aid in the Malignant Melanoma Prevention and Early Detection" IEEE 2014.

[5] F. S. Khan, J. van de Weijer, and M. Vanrell, "Top-down color attention for object recognition," in Proc. IEEE 12th Int. Conf. Comput. Vis., 2009, pp. 979-986.

[6] Sonia Singh, Priyanka Gupta,"Comparative study ID3, CART and C4.3 decision tree algorithm: A survey" International Journal of Advanced Information Science and Technology(IJAIST)Vol.27, No.20, July 2014.

[7] Gaurav L. Agrawal, prof. Hitesh Gupta,"Optimization of C4.5 detection tree algorithm for datamining application” International Journal for Emerging technology and advanced engg. Vol:3, issue: 3, Mar 2013.

[8] M. Bratkova, S. Boulos, and P. Shirley, "orgb: A practical opponent color space for computer graphics," IEEE Comput. Graph. Appl., vol. 29, no. 1,pp. 42-55, Jan./Feb. 2009.

[9] S.Jenicka andA.Suruliandi, "A Textural Approach for Land Cover Classification of Remotely Sensed Image,”. J. Comput.Vis., vol. 92, no. 10, pp. 47-52, May 2014.

[10] Rajvi Parikh, Dr Hitesh shah, "A Survey on Computer Vision Based Diagnosis for Skin Lesion Detection" International Journal of Engineering Science and Innovative Technology (IJESIT) Volume 2, Issue 2, March 2013.

[11] American Cancer Society. Cancer Facts \& Figures 2012. Atlanta: American Cancer Society; 2012.

[12] Dimitri A. Lisin, Marwan A. Mattar, Matthew B. Blaschko, Mark C. Benfield, Erik G. Learned-Miller, "Combining Local and Global Image Features for Object Class Recognition" IEEE 2013.

[13] Schindewolf T, Stolz W, Albert R, Abmayr W, Harms H, "Classification of melanocytic lesions with color and texture analysis using digital image processing” IEEE 1993.

[14] Damilola A. Okuboyejo, Olugbara, and Solomon A. Odunaike, "Automatic skin disease diagnosis using image classification" WCECS 2013.

[15] X. Yuan, Z. Yang, and G. Zouridakis, "SVM-based texture classification and application to early melanoma detection," in Proc. 28th IEEE EMBS Annu. Int. Conf., 2006, pp. 4775-4778. 